[Case report]

\title{
First trimester heterotopic pregnancy with shock treated laparoscopically, followed by uneventful term pregnancy and normal birth
}

\author{
Shinji Nomura ${ }^{1)}$, Hyo Kyozuka ${ }^{1)}$, Toki Jin ${ }^{1)}$, Mimori Fujimori' ${ }^{1)}$, Daisuke Suzuki ${ }^{1)}$, \\ Kenichi Sato $^{2)}$, Takashi Imamura ${ }^{2)}$ and Yasuhisa Nomura ${ }^{1)}$ \\ ${ }^{1)}$ Department of Obstetrics and Gynecology, Ohta Nishinouchi Hospital, Koriyama City, Fukushima, Ja- \\ pan ${ }^{2)}$ Department of Pediatrics, Ohta Nishinouchi Hospital, Koriyama City, Fukushima, Japan
}

(Received July 8, 2021, accepted September 28, 2021)

\begin{abstract}
Heterotopic pregnancy (HP), a coexistence of intrauterine and ectopic pregnancies, is extremely rare. Although there have been many reports of maternal outcomes in pregnant women with HP, they have not described fetal neurodevelopmental outcomes and survival. A 30-year-old Japanese woman in early gestation who had undergone two previous cesarean deliveries was transferred to our hospital with vital signs of shock. HP was confirmed by ultrasonography and laparoscopic surgery, and right salpingectomy was performed. At term, a 2,875 g neonate was delivered via cesarean section without any complications.
\end{abstract}

Key words : heterotopic pregnancy, neurological outcome, laparoscopic surgery

\section{Introduction}

Heterotopic pregnancy (HP) is defined as a combination of an intrauterine pregnancy and a concurrent ectopic pregnancy. It is a life-threatening condition that is difficult to diagnose ${ }^{1)}$. Spontaneous HP has been estimated to occur in $1 / 30,000$ pregnancies $^{2)}$. However, the actual incidence could be higher in women with predisposing risk factors, such as a history of : ectopic pregnancy, tubal surgery, pelvic inflammatory disease, or intrauterine device use ; in vitro fertilization associated with pregnancy; and smoking ${ }^{3,4)}$. Since HP might lead to life-threatening hemorrhage, which can increase maternal and fetal morbidity and mortality, early diagnosis and proper management are essential ${ }^{5,6}$.

Laparoscopy has been widely recognized as an indispensable tool in gynecologic care. Laparoscopic surgery has many advantages over conventional procedures, including smaller abdominal incisions, shorter duration of hospitalization, reduced postoperative pain and infection, and decreased risk of intraoperative bleeding ${ }^{7-9)}$. Although numerous cases with HP have been reported ${ }^{10-13}$, neonatal development after HP treated with laparoscopic surgery is inadequately documented.

Herein, we present a patient with HP accompanied by severe hemorrhage and shock during early pregnancy. The patient was successfully treated with laparoscopic surgery and carried her intrauterine pregnancy to term with no subsequent fetal abnormalities.

\section{Case presentation}

A 30-year-old multiparous Japanese woman (with one previous cesarean section due to dystocia) presented at seven weeks gestation to our emergency department with severe hyperemesis gravidarum and abnormal vital signs, including systolic blood pressure $<60 \mathrm{mmHg}$, heart rate $140 / \mathrm{min}$, respiratory rate $22 / \mathrm{min}$, and temperature $35.5^{\circ} \mathrm{C}$. She had used a follicle-stimulating agent to aid conception ; reasons why were not conveyed to us. Emergency

Corresponding author: Hyo Kyozuka, MD, PhD. E-mail : kyozuka@fmu.ac.jp

() 2021 The Fukushima Society of Medical Science. This article is licensed under a Creative Commons [Attribution-NonCommercial-ShareAlike 4.0 International] license.

https://creativecommons.org/licenses/by-nc-sa/4.0/ 
blood transfusion was performed. Transvaginal ultrasonography (TVU) revealed an intrauterine fetus with a heartbeat and large echo-free space in the pouch of Douglas (Figure 1A). Ovarian bleeding or torsion were considered in the context of conception after ovarian (hyper)stimulation. HP was suspected and it was unclear whether another fetus was present due to the large echo-free space in the pouch of Douglas. Therefore, we performed emergency diagnostic laparoscopy. Under general anesthesia, with the patient in lithotomy position, trocars were placed in the standard sites to avoid any injury to the uterus. In addition, manipulations were minimized to preserve intrauterine pregnancy.

Exploratory laparoscopy revealed severe hemoperitoneum, an opening in the proximal portion of the right fallopian tube, and trophoblastic tissue due to ruptured tubal pregnancy (Figure 1B). Immediate right salpingectomy was performed with transfu-

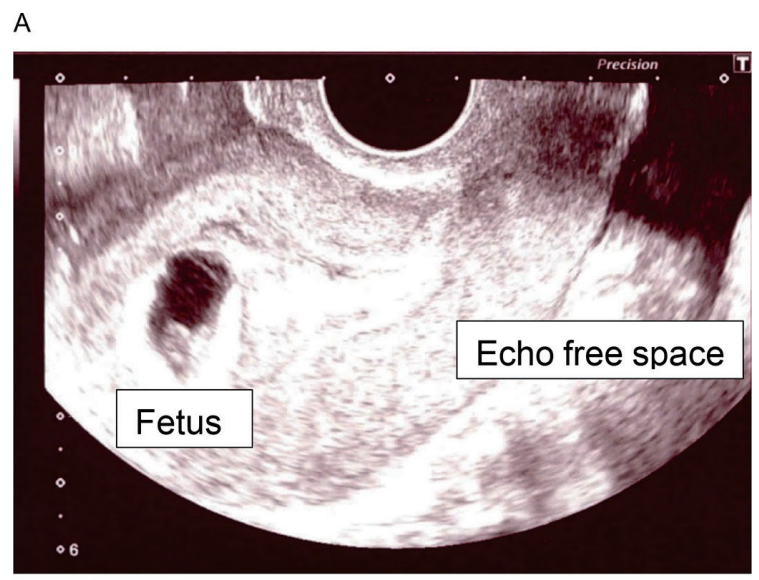

B

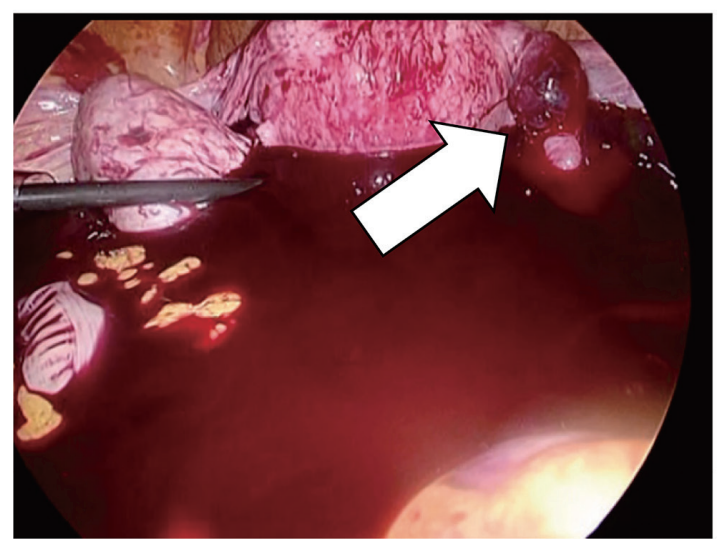

Fig. 1. A. Transvaginal sonogram shows a viable intrauterine fetus and free fluid in the pouch of Douglas.

B. Trophoblastic tissue due to ruptured ectopic pregnancy of the right proximal fallopian tube (arrow) with hemoperitoneum. sion of ten units each of red blood cells and fresh frozen plasma. (Blood component "units" in Japan are based on what can be derived from $200 \mathrm{~mL}$ of whole blood.) Total blood loss was $3,400 \mathrm{~mL}$. Immediately after surgery, we confirmed a fetal heartbeat using TVU. Pathological examination confirmed the diagnosis of tubal ectopic pregnancy. On day five after admission, a viable intrauterine fetus with a heartbeat was present, and the patient was discharged.

The patient received routine antepartum obstetric care, and the fetus showed no signs of heart rate abnormalities, such as decreased variability or absence of acceleration, on antenatal cardiotocography (CTG) at 32 weeks' gestation. Due to the maternal history of two previous cesarean deliveries, a cesarean section was performed at 38 weeks' gestation with no maternal complications. The neonate weighed 2,875 $\mathrm{g}$ at birth, which was appropriate for his gestational age ( 0.07 standard deviations) as per Japanese reference values ${ }^{14)}$, and had an Apgar score of 8 at both 1 and 5 minutes. The placenta weighed $460 \mathrm{~g}$, which was normal ( -0.73 standard deviations) as per Japanese standard curves of placental weight ${ }^{15)}$. Umbilical artery $\mathrm{pH}$, partial pressure of carbon dioxide, partial pressure of oxygen, and base excess were : 7.3, $57.0 \mathrm{mmHg}, 13.9 \mathrm{mmHg}$, and $-0.2 \mathrm{mmol} / \mathrm{L}$, respectively. The neonate exhibited no anomalies. The mother and neonate had an uneventful hospital course, and both of them were discharged 5 days after delivery.

\section{Discussion}

HP is a life-threatening condition that is difficult to diagnose. As suggested by our case, the use of ovulation induction agents might increase the risk of $\mathrm{HP}^{16)}$. However, establishing a diagnosis of $\mathrm{HP}$ is challenging. The main symptoms of HP are lower abdominal pain and vaginal bleeding. However, $\mathrm{HP}$ is sometimes asymptomatic ${ }^{17)}$, resulting in misdiagnosis, late diagnosis, and life-threatening intraabdominal hemorrhage ${ }^{18)}$. Wang et al. reported factors in three categories that most commonly cause delayed diagnosis or misdiagnosis of ectopic pregnancy : (i) clinician-related factors include misunderstanding of patients' medical history, insufficient training in ultrasonography, and poor awareness of patient's condition; (ii) patient-related factors include noncompliance with medical advice and lack of communication with clinicians and (iii) disease-related factors include complications of HP, atypical symptoms, delayed serum $\beta$-human 
chorionic gonadotropin level elevation, early rupture of cornual HP, asymptomatic ectopic pregnancy, and pregnancy of unknown location ${ }^{18)}$. To rule out ectopic pregnancy, it is important to carefully evaluate the adnexa using ultrasonography despite confirmation of an intrauterine gestational sac and apparent lack of any risk factor.

Although our patient presented with severe shock, we performed laparoscopic surgery, which allows detailed examination of pelvic and abdominal conditions, to identify the cause of the shock. Consequently, we could confirm that the abdominal bleeding was due to tubal rupture and repeated laparotomy, which might have increased maternal abdominal adhesions from two previous cesarean sections.

Our patient also experienced life-threatening intra-abdominal hemorrhage. Although several studies have reported cases of HP, because of its rarity, they have mainly focused on diagnostic accuracy and maternal outcomes ${ }^{17)}$. Little is known about neonatal outcomes. Maternal hypotension might cause fetal hypotension and hypoxemia, resulting in fetal cerebral hypoperfusion ${ }^{19}$. Fetal response to mild hypoxia is initially protective. In addition, fetal response to moderate hypoxia involves substantial compensations via the autonomic (parasympathetic [vagus] and sympathetic [beta-adrenergic]) nervous system ${ }^{20-23)}$. However, these compensatory mechanisms break down in the presence of severe asphyxia, and fetal brain damage can occur because central blood flow is not sufficiently maintained $^{24)}$. Since fetal heart rate variability and fetal heart rate acceleration indicate parasympathetic and sympathetic activity, respectively, brain damage may affect the CTG pattern ${ }^{16,17}$. Here, fetal heart rate variability and acceleration were consistently observed, suggesting that maintaining normal fetal oxygenation could improve prognosis ${ }^{25)}$. Severe fetal hypoxemia also causes local brain damage. Mallard et al. reported that severe umbilical occlusion for 10 min led to neuronal cell loss in the hippocampus in near-term fetal sheep ${ }^{26)}$, potentially affecting fetal development. Our patient's neonate showed no abnormalities in either antenatal fetal heart rate monitoring or fetal and placental growth, thus indicating a favorable neurological prognosis.

In conclusion, because HP is rare, little is known about its associated neonatal outcomes. This report highlights the successful laparoscopic management of severe hemorrhage in HP, followed by uneventful term gestation and a healthy singleton birth.

\section{Conflict of interest disclosure}

The authors have no conflicts of interest to declare.

\section{Contributors}

All authors were involved in the clinical care of the patient and contributed to the conception, drafting, review, and revision of the manuscript. All authors read and approved the final version of the manuscript and take full responsibility for the work.

\section{Funding}

This work did not receive any specific grants from funding agencies.

\section{Patient consent}

Informed consent was obtained from the patient for publication of this work.

\section{Provenance and peer review}

This case report was peer reviewed.

\section{References}

1. Soares C, Maçães A, Veiga MN, Osório M. Early diagnosis of spontaneous heterotopic pregnancy successfully treated with laparoscopic surgery. BMJ Case Rep, 13 : e239423, 2020.

2. Reece EA, Petrie RH, Sirmans MF, Finster M, Todd WD. Combined intrauterine and extrauterine gestations : a review. Am J Obstet Gynecol, 146 : 323-330, 1983.

3. Ankum WM, Mol BW, Van der Veen F, Bossuyt PM. Risk factors for ectopic pregnancy : a metaanalysis. Fertil Steril, 65: 1093, 1996.

4. Talbot K, Simpson R, Price N, Jackson SR. Heterotopic pregnancy. J Obstet Gynaecol, 31 : 712, 2011.

5. Kratschla-Apochal A, Nauer C, Bolla D. Heterotopic pregnancy after natural conception: a case report. Geburtshilfe Frauenheilkd, 72 : 639-642, 2012.

6. Nabi U, Yousaf A, Ghaffar F, Sajid S, Ahmed MMH. Heterotopic pregnancy - a diagnostic challenge. Six case reports and literature review. Cureus, 11: e6080, 2019.

7. Mais V, Ajossa S, Guerriero S, Mascia M, Solla E, Melis GB. Laparoscopic versus abdominal myomectomy : a prospective, randomized trial to 
evaluate benefits in early outcome. Am J Obstet Gynecol, 174 : 654-658, 1996.

8. Marret H, Chevillot M, Giraudeau B, Study Group of the French Society of Gynaecology and Obstetrics (Ouest Division). A retrospective multicentre study comparing myomectomy by laparoscopy and laparotomy in current surgical practice. What are the best patient selection criteria? Eur J Obstet Gynecol Reprod Biol, 117 : 82-86, 2004.

9. Yang W, Luo N, Ma L, Dai H, Cheng Z. The changes of surgical treatment for symptomatic uterine myomas in the past 15 years. Gynecol Minim Invasive Ther, 7 : 10-15, 2018.

10. Ramalho I, Ferreira I, Marques JP, et al. Live birth after treatment of a spontaneous ovarian heterotopic pregnancy : A case report. Case Rep Womens Health, 24 : e00144, 2019.

11. Dassah ET, Odoi AT, Darkey DE, Senaya CM, Djokoto RM. Spontaneous heterotopic pregnancy with live infant : report of two cases. East Afr Med J, 85 : 612-615, 2008.

12. Ikechukwu E, Adeleni M. Heterotopic pregnancy with live infant. Ann Afr Med, 12 : 43-45, 2013.

13. Guan Y, Ma C. Clinical Outcomes of Patients With Heterotopic Pregnancy After Surgical Treatment. J Minim Invasive Gynecol, 24 : 1111-1115, 2017.

14. Itabashi K, Miura F, Uehara R, Nakamura Y. New Japanese neonatal anthropometric charts for gestational age at birth. Pediatr Int, 56 : 702-708, 2014.

15. Ogawa M, Matsuda Y, Nakai A, Hayashi M, Sato S, Matsubara S. Standard curves of placental weight and fetal/placental weight ratio in Japanese population : difference according to the delivery mode, fetal sex, or maternal parity. Eur J Obstet Gynecol Reprod Biol, 206 : 225-223, 2016.

16. Wu Z, Zhang X, Xu P, Huang X. Clinical analysis of 50 patients with heterotopic pregnancy after ovulation induction or embryo transfer. Eur J Med Res, 23 : 17, 2018.

17. Li JB, Kong LZ, Yang JB, et al. Management of heterotopic pregnancy : experience from 1 tertiary medical center. Medicine (Baltimore), 95 : e2570, 2016.

18. Wang LL, Chen X, Ye DS, et al. Misdiagnosis and delayed diagnosis for ectopic and heterotopic pregnancies after in vitro fertilization and embryo transfer. J Huazhong Univ Sci Technolog Med Sci, 34 : 103-107, 2014.

19. Jones M Jr, Sheldon RE, Peeters LL, Meschia G, Battaglia FC, Makowski EL. Fetal cerebral oxygen consumption at different levels of oxygenation. J Appl Physiol Respir Environ Exerc Physiol, 43 : 1080-1084, 1977.

20. Kyozuka H, Yasuda S, Hiraiwa T, Nomura Y, Fujimori K. The change of fetal heart rate short-term variability during the course of histological chorioamnionitis in fetal sheep. Eur J Obstet Gynecol Reprod Biol, 228 : 32-37, 2018.

21. Yasuda S, Kyozuka H, Nomura Y, Fujimori K. Effect of magnesium sulfate on baroreflex during acute hypoxemia in chronically instrumented fetal sheep. J Obstet Gynaecol Res, 46 : 1035-1043, 2020.

22. Figueroa-Diesel H, Hernandez-Andrade E, Acosta-Rojas R, Cabero L, Gratacos E. Doppler changes in the main fetal brain arteries at different stages of hemodynamic adaptation in severe intrauterine growth restriction. Ultrasound Obstet Gynecol, 30 : 297-302, 2007.

23. Jackson BT, Piasecki GJ, Novy MJ. Fetal responses to altered maternal oxygenation in rhesus monkey. Am J Physiol, 252 : R94-101, 1987.

24. Yaffe H, Parer JT, Block BS, Llanos AJ. Cardiorespiratory responses to graded reductions of uterine blood flow in the sheep fetus. J Dev Physiol, 9 : 325-336, 1987.

25. American College of Obstetricians and Gynecologists. Practice bulletin no. 116: Management of intrapartum fetal heart rate tracings. Obstet Gynecol, 116 : 1232-1240, 2010.

26. Mallard EC, Gunn AJ, Williams CE, Johnston BM, Gluckman PD. Transient umbilical cord occlusion causes hippocampal damage in the fetal sheep. Am J Obstet Gynecol, 167 : 1423-1430, 1992. 